\title{
The Influence of Face Shields on the Quality of Colonoscopy in the Era of the COVID-19 Pandemic
}

\author{
Jin Wook Lee ${ }^{1}$, Hyo Jeong Lee ${ }^{2}$, Dae Sung Kim¹, Jiyoung Yoon ${ }^{1}$, Seung Wook Hong' ${ }^{1}$, Ha Won Hwang ${ }^{1}$, \\ Jong-Soo Lee², Gwang-Un Kim², Sinwon Lee ${ }^{2}$, Jaewon Choe'2, Jin Hwa Park', Dong-Hoon Yang', and Jeong-Sik Byeon ${ }^{1}$ \\ ${ }^{1}$ Department of Gastroenterology, Asan Medical Center, University of Ulsan College of Medicine, and ${ }^{2}$ Division of Gastroenterology, \\ Health Screening and Promotion Center, Asan Medical Center, Seoul, Korea
}

Article Info
Received February 8, 2021
Revised May 20, 2021
Accepted June 14, 2021
Published online August 25, 2021
Corresponding Author
Jeong-Sik Byeon
ORCID https://orcid.org/0000-0002-9793-6379
E-mail jsbyeon@amc.seoul.kr
Jin Wook Lee and Hyo Jeong Lee contributed
equally to this work as first authors.

Article Info

Accepted June 14, 2021

equally to this work as first authors.
Background/Aims: The worldwide coronavirus disease 2019 pandemic has led endoscopists to use personal protective equipment (PPE) for infection prevention. This study aimed to investigate whether wearing a face shield as PPE affects the quality of colonoscopy.

Methods: We reviewed the medical records and colonoscopy findings of patients who underwent colonoscopies at Asan Medical Center, Korea from March 10 to May 31, 2020. The colonoscopies in this study were performed by five gastroenterology fellows and four expert endoscopists. We compared colonoscopy quality indicators, such as withdrawal time, adenoma detection rate (ADR), mean number of adenomas per colonoscopy (APC), polypectomy time, and polypectomy adverse events, both before and after face shields were added as PPE on April 13, 2020.

Results: Of the 1,344 colonoscopies analyzed, 715 and 629 were performed before and after the introduction of face shields, respectively. The median withdrawal time was similar between the face shield and no-face shield groups (8.72 minutes vs 8.68 minutes, $p=0.816)$, as was the ADR $(41.5 \%$ vs $39.8 \%, p=0.605)$ and APC ( 0.72 vs $0.77, p=0.510)$. Polypectomy-associated quality indicators, such as polypectomy time and polypectomy adverse events were also not different between the groups. Quality indicators were not different between the face shield and no-face shield groups of gastroenterology fellows, or of expert endoscopists.

Conclusions: Colonoscopy performance was not unfavorably affected by the use of a face shield. PPE, including face shields, can be recommended without a concern about colonoscopy quality deterioration. (Gut Liver 2022;16:404-413)

Key Words: Colonoscopy; COVID-19; Face shield; Personal protective equipment; Quality

\section{INTRODUCTION}

The worldwide pandemic of novel coronavirus disease 2019 (COVID-19) in 2020 has caused significant changes in clinical practice of medicine, including gastroenterology. ${ }^{1}$ Severe acute respiratory syndrome-related coronavirus 2, which can transmit from human to human, poses a higher risk of infection among healthcare professionals than among the general population. ${ }^{2,3}$ Wearing face masks and eye protection in the healthcare setting reduced this high risk of virus infection in healthcare professionals. ${ }^{4}$ Therefore, the U.S. Centers for Disease Control and Prevention recommended that healthcare professionals should use appropriate personal protective equipment (PPE) as a routine infection prevention and control practice during the COVID-19 pandemic. $^{5}$

In the gastrointestinal endoscopy unit, healthcare professionals are in close contact with patients and gastrointestinal endoscopies, such as esophagogastroduodenoscopy, endoscopic retrograde cholangiopancreatography, and colonoscopy, are potentially aerosol-generating procedures, with increased risk of transmission of COVID-19. ${ }^{6}$ Therefore, professional societies of gastroenterology worldwide have recommended strategies for infection prevention and control in the gastrointestinal endoscopy unit and appropriate protocol utilizing PPE for healthcare professionals 
during the COVID-19 pandemic. $^{7-10}$ Representative PPE includes surgical masks, face shields, isolation gowns, and disposable gloves.

Colonoscopy is the principal diagnostic tool for various colorectal diseases. In addition, colonoscopy is one of the most important screening methods for colorectal cancer. The fundamental role of screening colonoscopy is detection of colorectal neoplasms, including cancers and polyps. Another important function of colonoscopy is endoscopic resection of colorectal polyps and T1 colorectal cancers with low risk of lymph node metastasis. The quality of colonoscopy is of utmost importance to satisfy the goals of screening and therapeutic colonoscopies, ${ }^{11}$ such as qualified detection of colorectal neoplasm, without missed lesions and complete endoscopic resection of colorectal neoplasm, without serious adverse events. Several quality indicators, such as the adenoma detection rate (ADR) and withdrawal time, have been implemented to monitor the quality of colonoscopy. ${ }^{12,13}$ Because the face shield is a PPE that was not used frequently in endoscopy units before the COVID-19 pandemic, endoscopists are not accustomed to it. Thus, there can be a reasonable concern that wearing a face shield may be cumbersome and induce impaired visibility to endoscopists, thereby worsening the quality of colonoscopy.

In this study, we investigated whether wearing the face shield might affect the quality of colonoscopy, by assessing ADR and withdrawal time with and without the face shield. We also evaluated the effect of the face shield on therapeutic colonoscopies, such as polypectomy.

\section{MATERIALS AND METHODS}

\section{Study design and patients}

This was a single center, retrospective cohort study that compared the quality of colonoscopy depending on whether a face shield was added as a PPE. Disposable latex gloves, isolation gown, and surgical mask were worn as PPE before the COVID-19 pandemic at Asan Medical Center, Seoul, Korea. Since the COVID-19 outbreak in Daegu, Korea in late February 2020, the KF94 mask (Dr. Puri $^{\circledR}$ KF [Korea Filter] 94, KM Healthcare Corp, Seoul, Korea), which has equivalent efficacy to the N95 mask, was worn instead of the surgical mask. ${ }^{14}$ Because a nationwide outbreak continued, a face shield (Sview, RoitsNine Corp., Seoul, Korea) was added, from April 13, 2020, to reinforce the PPE. The face shield, Sview, is made of transparent polyethylene terephthalate material (Fig. 1). Thus, at our institution, disposable latex gloves, an isolation gown, and a KF94 mask were worn as PPE between late February and
April 12, 2020 whereas a face shield was added to this from April 13, 2020.

We reviewed the medical records and colonoscopy results of consecutive subjects who underwent colonoscopies at the Department of Gastroenterology and Health Screening and Promotion Center in our institution from March 10 to May 31, 2020. Of these, we included colonoscopies conducted by five 2nd-year gastroenterology fellows as the trainee endoscopist group at the Department of Gastroenterology, who had previously performed 300 to 500 colonoscopy procedures before March 2020. As the expert endoscopist group, we included colonoscopies performed at the Health Screening and Promotion Center by four board-certified gastroenterologists with experience of 4,000 or more colonoscopies over a period of 6 years or longer. As described above, colonoscopies performed between March 10 and April 12, 2020 were included in the no-face shield group and those performed between April 13 to May 31, 2020 were included in the face shield group. We compared colonoscopy quality indicators between the face shield and no-face shield groups.

The inclusion criteria of this study were patients who underwent screening and surveillance colonoscopies. Patients who underwent diagnostic colonoscopies because of mild gastrointestinal symptoms, such as vague low abdominal discomfort, were also included. The exclusion criteria were (1) patients under 18 years of age, (2) patients with previous colectomy, (3) patients with inflammatory bowel disease and colorectal polyposis syndrome, (4) patients with moderate to severe symptoms such as overt gastrointestinal bleeding, (5) patients referred from a primary clinic for treatment of colorectal polyp and/or cancer, and

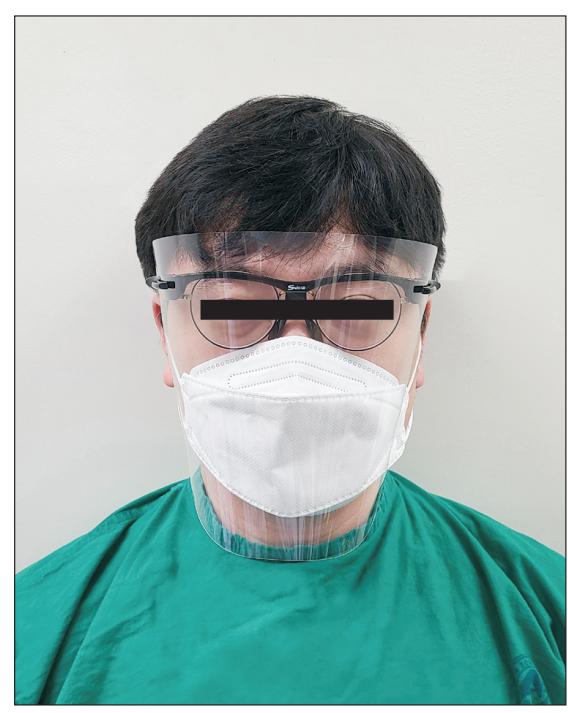

Fig. 1. Wearing of a face shield (Sview, RoitsNine Corp.). 
(6) patients with a screening colonoscopy within 5 years. Patients whose colonoscopy was incomplete because of inadequate bowel preparation (Boston Bowel Preparation Scale $<6)^{15}$ were also excluded. The Institutional Review Board of Asan Medical Center (IRB number: 2020-1228) approved this study and waived the requirement for informed consent.

\section{Colonoscopy procedure}

All colonoscopies were performed using an Olympus CF-HQ290I or CF-HQ290L colonoscope (Olympus Optical, Co., Ltd., Tokyo, Japan). Bowel preparation was performed with $2 \mathrm{~L}$ polyethylene glycol plus ascorbic acid solution (Coolprep ${ }^{\circledR}$; Taejoon Pharm, Seoul, Korea). After observing the anus and taking a picture, the colonoscope was inserted in a standard method up to the cecum. After a photograph of the cecum was taken, the observation of colonic mucosa was made during the colonoscope withdrawal. The size, location, number, and morphology of all colonic lesions were documented during colonoscopy. When a polyp was detected, endoscopists could use narrow band imaging at his or her discretion for detailed assessment of real-time histological diagnosis. The size of a polyp was estimated by open biopsy forceps or the diameter of the snare catheter. Polypectomy was performed using cold forceps polypectomy, cold snare polypectomy, and endoscopic mucosal resection depending on the size and morphology of polyps and the endoscopist's preference. Histological evaluation of resected polyp was performed by board-certified gastrointestinal pathologists.

\section{Study outcomes}

The primary outcomes of interest were ADR and withdrawal time. ADR was defined as the proportion of colonoscopies with at least one adenoma detected. Withdrawal time was defined as the time to observe the colon lumen from the cecum to the rectum, excluding the polypectomy time. Secondary outcomes included the polyp detection rate (PDR), advanced adenoma detection rate (AADR), mean number of polyps per colonoscopy, mean number of adenomas per colonoscopy (APC), and cecal insertion time. Advanced adenomas were defined as adenomas larger than $10 \mathrm{~mm}$ and adenomas containing a villous component, high-grade dysplasia, or carcinoma. Insertion time was defined as the time for the colonoscope to reach the cecum from the anus. Polypectomyassociated indicators were also investigated, which included endoscopically complete resection, polypectomy time, and postpolypectomy adverse events. Polypectomy time was defined as the time from polyp detection to completion of its resection. Procedural time data were investigated by using the time recorded at colonoscopy photographs.

\section{Statistical analysis}

The primary study goal was to compare the mean withdrawal time and ADR between the face shield and no-face shield groups. To calculate the number of study patients, we assumed the mean withdrawal time was 7.8 minutes based on previous studies in which colonoscopy was performed without the face shield. ${ }^{16,17}$ Increase of withdrawal time by 0.5 minutes or less was considered clinically noninferior. Enrollment of 1,200 patients, i.e., 600 in each arm, were needed to detect such a difference between groups assuming a standard deviation of 3.1 with $80 \%$ power and a $5 \%$ level of significance.

Descriptive statistics were used for the demographic characteristics. Normally distributed variables were presented as means with standard deviation, and non-normally distributed variables were presented as medians with interquartile ranges (IQRs). Continuous variables were compared using the Student $t$ test or the Mann-Whitney U test as appropriate. Categorical variables were presented as proportion of the total study population. Proportions were compared using the chi-squared test or the Fisher exact test as appropriate. A p-value of $<0.05$ was considered sta-

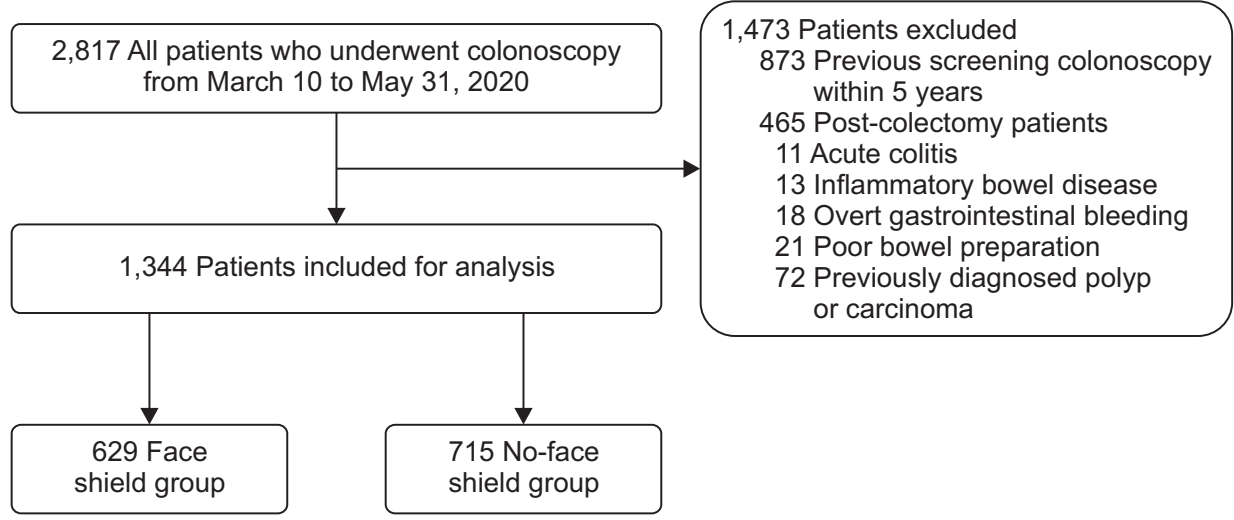

Fig. 2. Inclusion and exclusion of study participants. 


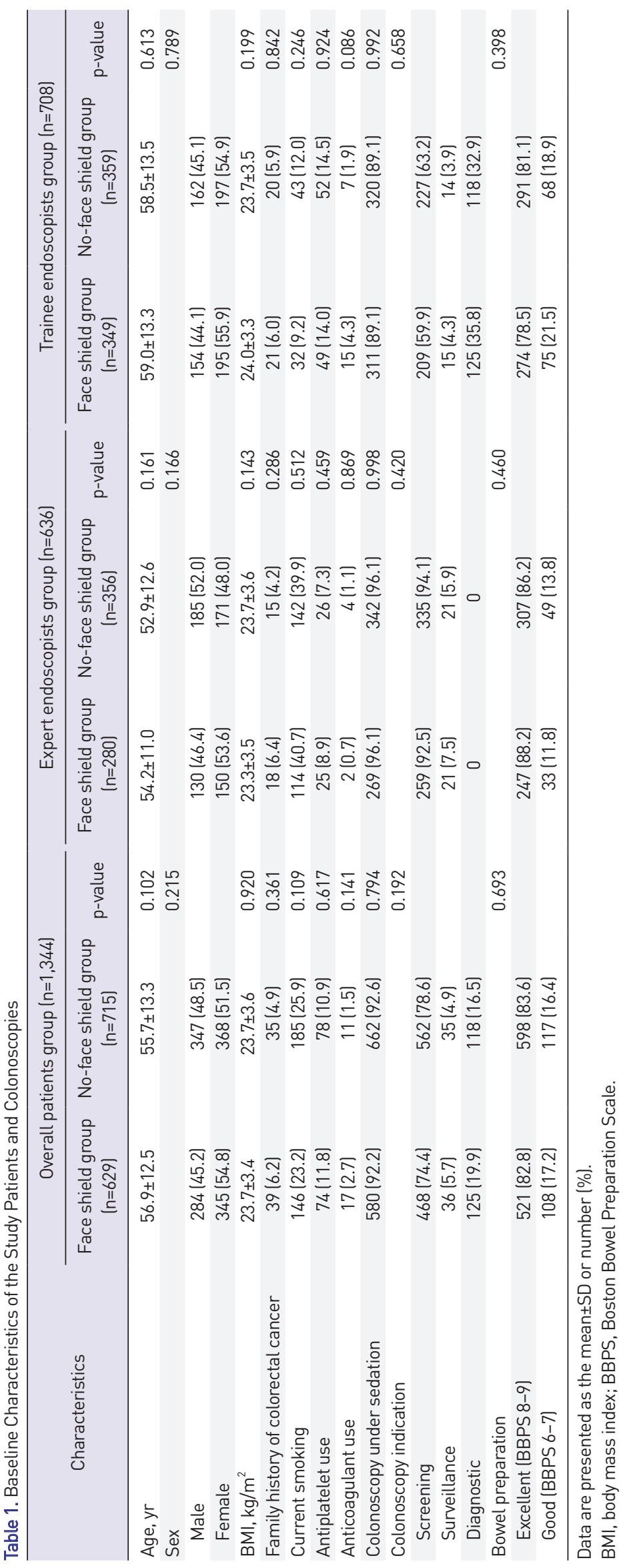


tistically significant. All data were analyzed using the IBM SPSS version 21 software (IBM Corp., Armonk, NY, USA).

\section{RESULTS}

\section{Baseline characteristics}

The nine endoscopists who participated in this study performed 2,817 colonoscopies in 2,817 patients from March 10 to May 31, 2020. We excluded 1,473 patients based on the exclusion criteria. Therefore, a total of 1,344 colonoscopies were included in the final analysis of this study. Of these, 715 colonoscopies were performed before introduction of the face shield, and 629 colonoscopies after introduction of the face shield (Fig. 2). Baseline characteristics, such as age, sex, and family history of colorectal cancer, were similar between the face shield and no-face shield groups. The proportions of screening, surveillance, and diagnostic colonoscopy were also not different between the two groups. They were also similar between subgroups according to the expertise level of endoscopists (Table 1). We investigated the average number of total colonoscopy examinations per day at our center before and after wearing the face shield during the study period. The numbers were not different between the two periods $(39.2 \pm 3.2$ vs 40.4 $\pm 3.7, \mathrm{p}=0.233)$. The average numbers of colonoscopies by one endoscopist in one session (270 to 300 minutes) were also not different before and after wearing the face shield ( $4.0 \pm 1.6$ vs $3.9 \pm 1.5, \mathrm{p}=0.626$ ). Moreover, there were no patients with COVID-19 symptoms and/or confirmed COVID-19 during the study period.

\section{Quality indicators associated with colonoscopy observation}

ADR was similar between the face shield and no-face shield groups ( $41.5 \%$ vs $39.8 \%, \mathrm{p}=0.605)$. Additionally, ADR was calculated only in the screening colonoscopy populations in the face shield $(\mathrm{n}=468)$ and no-face shield groups $(\mathrm{n}=562)$, which showed similar ADR $(38.9 \%$ [30.2\% to $45.8 \%$ ] vs $37.9 \%$ [ $30.6 \%$ to $44.6 \%$ ], $\mathrm{p}=0.880$ ). There was no significant difference in PDR between both groups ( $48.3 \%$ vs $50.5 \%, \mathrm{p}=0.863)$. AADR was also similar ( $5.1 \%$ vs $3.8 \%, \mathrm{p}=0.387$ ) (Table 2). The distribution of ADR, PDR, and AADR of nine endoscopists according to wearing and non-wearing of a face shield is presented in Fig. 3. The APC $(0.72 \pm 1.27$ vs $0.77 \pm 1.38, \mathrm{p}=0.510)$ and polyps per colonoscopy ( $1.06 \pm 1.61$ vs $1.14 \pm 1.75, \mathrm{p}=0.386)$ were also not different between both groups.

The median withdrawal time was similar between the face shield and no-face shield groups (8.72 minutes [IQR, 7.32 to 10.87 ] vs 8.68 minutes [IQR, 7.37 to 10.93 ], $\mathrm{p}=0.816$ ). The proportion of cases with withdrawal time $<6$ minutes was not different between the two groups $(0.8 \%$ vs $1.5 \%, \mathrm{p}=0.210)$. The cecal intubation rate was similar between the two groups ( $100 \%$ vs $99.7 \%, \mathrm{p}=0.184)$. The median cecal insertion time was also not different between the groups (Table 2).

Colonoscopy quality indicators were compared between the face shield and no-face shield groups according to the colonoscopy expertise level. There was no significant difference in all quality indicators such as insertion time,

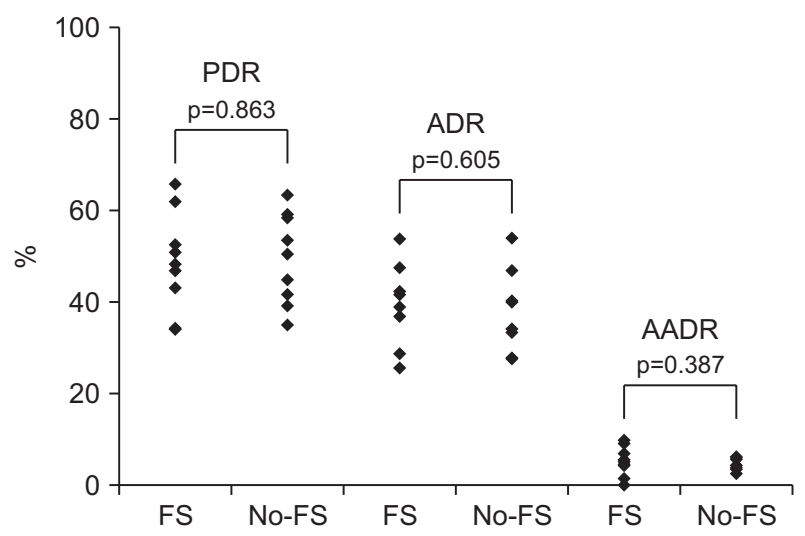

Fig. 3. Distribution of PDR, ADR, and AADR according to whether a face shield was worn.

PDR, polyp detection rate; $A D R$, adenoma detection rate; $A A D R$, advanced adenoma detection rate; FS, face shield; No-FS, no-face shield.

Table 2. Quality Indicators Associated with Colonoscopy Observation

\begin{tabular}{lccc}
\multicolumn{1}{c}{ Variable } & Face shield group (n=629) & No-face shield group (n=715) & $\mathrm{p}$-value \\
\hline Cecal intubation rate & $629(100)$ & $713(99.7)$ & 0.184 \\
Cases with withdrawal time $<6$ min & $5(0.8)$ & $11(1.5)$ & 0.210 \\
Insertion time, min & $5.57(3.83-8.65)$ & $5.40(3.53-8.30)$ & 0.131 \\
Withdrawal time, min & $8.72(7.32-10.87)$ & $8.68(7.37-10.93)$ & 0.816 \\
Polyp detection rate, \% & $48.3(38.7-57.3)$ & $50.5(40.4-58.7)$ & 0.863 \\
Adenoma detection rate, \% & $41.5(32.8-44.9)$ & $39.8(30.5-43.6)$ & 0.605 \\
Advanced adenoma detection rate, \% & $5.1(2.8-8.0)$ & $3.8(2.6-5.6)$ & 0.387 \\
Polyps per colonoscopy & $1.06 \pm 1.61$ & $1.14 \pm 1.75$ & 0.386 \\
Adenomas per colonoscopy & $0.72 \pm 1.27$ & $0.77 \pm 1.38$ & 0.510
\end{tabular}

Data are presented as the number (\%), median (interquartile range), or mean \pm SD. 
Table 3. Comparison of Quality Indicators between the Face Shield and No-Face Shield Groups According to the Colonoscopy Expertise Level

\begin{tabular}{|c|c|c|c|c|c|c|}
\hline \multirow[b]{2}{*}{ Variable } & \multicolumn{3}{|c|}{ Expert endoscopists ( $n=636$ ) } & \multicolumn{3}{|c|}{ Trainee endoscopists (n=708) } \\
\hline & $\begin{array}{l}\text { Face shield group } \\
\qquad(\mathrm{n}=280)\end{array}$ & $\begin{array}{l}\text { No-face shield group } \\
\qquad(\mathrm{n}=356)\end{array}$ & $\mathrm{p}$-value & $\begin{array}{l}\text { Face shield group } \\
\qquad(\mathrm{n}=349)\end{array}$ & $\begin{array}{l}\text { No-face shield group } \\
\qquad(\mathrm{n}=359)\end{array}$ & $\mathrm{p}$-value \\
\hline Cecal intubation rate & $280(100)$ & 355 (99.7) & 0.375 & 349 (100) & 358 (99.7) & 0.324 \\
\hline Cases with withdrawal time $<6$ min & $3(1.1)$ & $5(1.4)$ & 0.708 & $2(0.6)$ & $6(1.7)$ & 0.167 \\
\hline Insertion time, min & $4.38(3.30-5.97)$ & $4.00(3.05-5.52)$ & 0.259 & $7.15(4.97-10.83)$ & $7.33(5.22-11.22)$ & 0.833 \\
\hline Withdrawal time, min & $7.73(6.88-8.97)$ & 7.87 (6.92-9.12) & 0.855 & $9.80(8.25-12.12)$ & 10.08 (8.17-12.87) & 0.711 \\
\hline Polyp detection rate, \% & $56.4(47.8-64.7)$ & $52.0(43.8-60.8)$ & 0.686 & $43.1(34.1-50.4)$ & 44.9 (37.1-58.7) & 0.421 \\
\hline Adenoma detection rate, $\%$ & $42.0(41.5-50.9)$ & $40.1(35.5-45.3)$ & 0.200 & $36.8(27.2-43.2)$ & $33.3(27.7-46.9)$ & 0.882 \\
\hline Advanced adenoma detection rate, $\%$ & $5.0(2.2-8.2)$ & $3.9(2.8-5.7)$ & 0.686 & $5.1(2.1-8.3)$ & $3.8(2.5-5.6)$ & 0.548 \\
\hline Polyps per colonoscopy & $1.20 \pm 1.59$ & $1.22 \pm 1.87$ & 0.896 & $0.94 \pm 1.61$ & $1.05 \pm 1.62$ & 0.353 \\
\hline Adenomas per colonoscopy & $0.80 \pm 1.24$ & $0.87 \pm 1.55$ & 0.520 & $0.66 \pm 1.28$ & $0.67 \pm 1.17$ & 0.918 \\
\hline
\end{tabular}

Data are presented as the number (\%), median (interquartile range), or mean \pm SD.

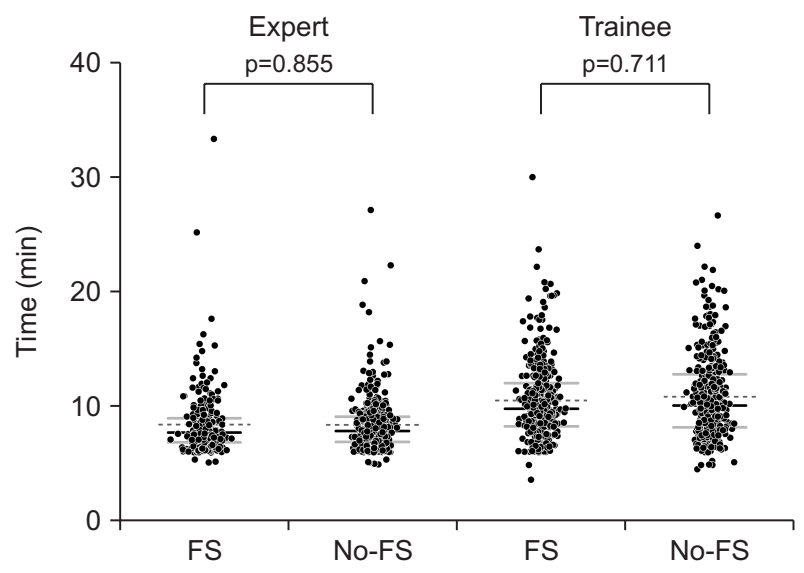

Fig. 4. Comparison of withdrawal time between the face shield (FS) and no-face shield (No-FS) groups according to the endoscopist expertise levels. The dotted line in each dot plot represents the mean level. The black line in each dot plot represents the median level. The grey lines in each dot plot represent the $25 \%$ and $75 \%$ quartile levels.

withdrawal time, PDR, ADR, and AADR between the face shield and no-face shield groups of four experienced board-certified gastroenterologists. Similarly, all quality indicators were not different between the face shield and no-face shield groups of trainee endoscopists, i.e., five 2ndyear gastroenterology fellows (Table 3, Fig. 4).

\section{Polypectomy-associated quality indicators}

A total of 590 and 734 polyps were detected and resected endoscopically in 306 patients of the face shield group and 355 patients of the no-face shield group, respectively. Distribution of polyp size was similar between the groups (polyps $\leq 5 \mathrm{~mm}, 81.9 \%$ vs $82.0 \%$; polyps of $6-9 \mathrm{~mm}, 14.4 \%$ vs $15.3 \%$; polyps $\geq 10 \mathrm{~mm}, 3.7 \%$ vs $2.7 \%$; $\mathrm{p}=0.549$ ). Cold forceps polypectomy was the most frequently used resection technique in both groups $(72.4 \%$ vs $73.3 \%)$, followed by cold snare polypectomy (13.6\% vs $12.3 \%$ ) and endoscopic mucosal resection (14.0\% vs $14.4 \%)$. The propor- tion of each polypectomy technique was similar between the groups ( $\mathrm{p}=0.779$ ). All polyps were endoscopically completely resected in both groups.

Median procedure time of cold forceps polypectomy was similar between the face shield and no-face shield groups ( 0.80 minutes [IQR, 0.60 to 1.16 ] vs 0.83 minutes [IQR, 0.63 to 1.23 ], $\mathrm{p}=0.475$ ). Median cold snare polypectomy time and endoscopic mucosal resection time were also not different between the face shield and no-face shield groups (Table 4). In addition, there were no cases of adverse events, including perforation and delayed bleeding, in either group.

\section{DISCUSSION}

In this retrospective cohort study, we found that colonoscopy with the face shield worn did not increase the withdrawal time or decrease the ADR. In addition, insertion time, PDR, AADR, and mean numbers of polyps per colonoscopy and APC were not different between the face shield and no-face shield groups. Furthermore, the polypectomy time and incidence of post-polypectomy adverse events were also not different between both groups. These findings suggest that wearing the face shield may not unfavorably affect the quality of colonoscopy.

High-quality colonoscopy and quality improvement programs are of paramount importance to accomplish the goal of colonoscopy effectively, including complete detection and removal of colorectal neoplasm. ${ }^{18}$ Several quality indicators were developed to measure the quality of colonoscopy, which include ADR, PDR, AADR, APC, and withdrawal time. Because increased ADR is associated with a reduced risk of interval colorectal cancer and death, ${ }^{19} \mathrm{ADR}$ has been the most widely used quality indicator. ${ }^{12,20}$ ADR levels (41.5\% and $39.8 \%$, respectively) in 
Table 4. Polypectomy-Associated Variables

\begin{tabular}{|c|c|c|c|}
\hline Variable & $\begin{array}{l}\text { Face shield group } \\
\text { (590 polyps in } 306 \text { patients) }\end{array}$ & $\begin{array}{l}\text { No-face shield group } \\
\text { (734 polyps in } 355 \text { patients) }\end{array}$ & p-value \\
\hline Polyp size & & & 0.549 \\
\hline$\leq 5 \mathrm{~mm}$ & 483 (81.9) & $602(82.0)$ & \\
\hline $6-9 \mathrm{~mm}$ & 85 (14.4) & $112(15.3)$ & \\
\hline$\geq 10 \mathrm{~mm}$ & $22(3.7)$ & $20(2.7)$ & \\
\hline Mean polyp size, $\mathrm{mm}$ & $4.11 \pm 2.10$ & $4.04 \pm 1.90$ & 0.545 \\
\hline Endoscopically complete resection & $590(100)$ & $734(100)$ & NA \\
\hline Polypectomy technique & & & 0.779 \\
\hline Cold forceps & 427 (72.4) & 538 (73.3) & \\
\hline Cold snare & $80(13.6)$ & 90 (12.3) & \\
\hline EMR & $83(14.0)$ & $106(14.4)$ & \\
\hline \multicolumn{4}{|c|}{ Mean polyp size in each polypectomy method, $\mathrm{mm}$} \\
\hline Cold forceps polypectomy & $3.20 \pm 0.95$ & $3.28 \pm 1.03$ & 0.254 \\
\hline Cold snare polypectomy & $4.96 \pm 1.28$ & $4.82 \pm 1.15$ & 0.455 \\
\hline EMR & $7.94 \pm 2.50$ & $7.24 \pm 2.30$ & 0.054 \\
\hline \multicolumn{4}{|l|}{ Procedure time, $\min$} \\
\hline Cold forceps polypectomy & $0.80(0.60-1.16)$ & $0.83(0.63-1.23)$ & 0.475 \\
\hline Cold snare polypectomy & $1.66(1.50-2.55)$ & $1.95(1.38-3.02)$ & 0.301 \\
\hline EMR & $3.83(3.13-5.5)$ & $3.65(3.07-5.35)$ & 0.567 \\
\hline \multicolumn{4}{|l|}{ Adverse events } \\
\hline Perforation & 0 & 0 & NA \\
\hline Delayed bleeding & 0 & 0 & NA \\
\hline
\end{tabular}

Data are presented as the number (\%), mean $\pm S D$, or median (interquartile range).

$E M R$, endoscopic mucosal resection; NA, not applicable.

both groups in our study were higher than the target level (25\%; $30 \%$ for men and 20\% for women) recommended by American Society for Gastrointestinal Endoscopy and American College of Gastroenterology ${ }^{12}$ However, they were similar to those in previous screening colonoscopy studies performed in Korea (37.2\% to $45.3 \%)$, ${ }^{16,17}$ which suggests that endoscopists and patients in our study were not skewed or biased and that our findings can be generalized to other endoscopy units. We believe recent education about the importance of colonoscopy quality in the gastroenterology society may be the main reason for the high ADR. In previous studies, ADR was reported to be associated with factors such as a patient's age, sex, bowel preparation adequacy, and the endoscopist-related technical factors, including cecal intubation rate and withdrawal time. ${ }^{21-25}$ These factors did not differ between the face shield and noface shield groups in our study. Furthermore, the number of colonoscopies at our center was not different before and after wearing the face shield, which suggests no difference in the workload, a possible confounding variable in the analysis of ADR, between the two periods. In addition, the proportion of diagnostic colonoscopy for patients with gastrointestinal symptoms was also not different between the face shield and no-face shield groups, which decreases the risk of selection bias. As a corollary, we suggest that fair comparison of ADR was made, which may objectively imply the absence of an unfavorable effect of the face shield on ADR.

Other quality indicators, such as PDR, AADR, APC, and withdrawal time, were also similar between the face shield and no-face shield groups. PDR is an easily obtainable quality indicator, because it does not require histopathology results, unlike ADR. AADR is another important quality indicator because advanced adenoma was reported to transit to colorectal cancer by $2.6 \%$ to $5.8 \%$ annually. ${ }^{26}$ APC was raised as another quality indicator that might complement ADR, because there was a concern that concentration on detecting additional adenomas after detection of the first adenoma could decrease, and that ADR could not reflect the quality of the entire colonic examination. American Society for Gastrointestinal Endoscopy and American College of Gastroenterology recommended a mean withdrawal time $>6$ minutes for adequate observation and detection of colorectal neoplasms. ${ }^{12}$ Although there were a few colonoscopy cases with withdrawal time $<6$ minutes in the face shield and no-face shield groups, the proportions were similar ( $0.8 \%$ vs $1.5 \%, \mathrm{p}=0.210)$. This suggests that the discomfort from face shield may not have shortened the colonoscopy withdrawal time, which implies no negative effect of the face shield on colonoscopy quality indicators. Because not only ADR but also all these other important quality indicators, did not differ between the face shield and no-face shield groups, we suggest with high confidence that the face shield may not unfavorably af- 
fect the quality of colonoscopy. The similar insertion time between the two groups in our study further supports the absence of a negative effect from the face shield.

We investigated polypectomy-associated indicators to evaluate the effect of the face shield not only on the quality of screening/surveillance/diagnostic colonoscopy but also on that of therapeutic colonoscopy. All polyps could be completely resected endoscopically in both groups. Endoscopic resection procedure times were not different between the groups. In addition, polypectomy-associated adverse events did not occur in either group. These findings suggest that both the efficacy and safety of polypectomy may be similar between the face shield and no-face shield groups, implying that the face shield may not interfere with colonoscopic polypectomy.

We initially assumed that the face shield might interfere with the quality of vision of endoscopists, thereby lengthening the withdrawal time and decreasing the ADR. We also hypothesized that less-experienced endoscopists, such as trainees, could be influenced more significantly by the face shield. Therefore, we performed subgroup analyses according to the expertise level of endoscopists. Unlike what was expected not only experienced endoscopists but also second-year gastroenterology fellows were unaffected by the face shield in terms of colonoscopy quality. Although we found the absence of colonoscopy quality deterioration by the face shield consistently in both observation and resection of colorectal neoplasm and in both expert and beginner endoscopists, the reason for this finding is not clear. A Turkish study investigated the effect of face shields on the field-of-view of neurosurgeons when using a surgical microscope. ${ }^{27}$ The field-of-view significantly decreased from that of the naked eye $\left(9,305.33 \pm 406.1 \mathrm{~mm}^{2}\right)$ to that with a face shield $\left(92.33 \pm 6.4 \mathrm{~mm}^{2}\right)$. Another study in the United Kingdom evaluated the effect of face shields on the field-of-vision of otolaryngologists using a microscope. ${ }^{28}$ The face shield reduced the field-of-vision up to $76.8 \%$. These two studies suggest that the face shield is not compatible with the use of a surgical microscope, because it decreases the visual field by increasing the distance between the eye piece and pupil. Unlike the situation of microsurgeries utilizing a microscope, the distance between the endoscopy monitor and the endoscopist's pupil is 1 to $2 \mathrm{~m}$ in colonoscopy rooms, thereby possibly minimizing the risk of a clinically relevant unfavorable effect of the face shield. We suggest that this may explain the absence of colonoscopy quality deterioration while wearing the face shield. A study in Colombia that investigated the effect of eyeprotecting PPE on quality of vision of gastroenterologists supports this assumption. ${ }^{29}$ In this study, the quality of vision assessed by an ophthalmological examination did not worsen when using the $3 \mathrm{M} 6800$ full facepiece. However, wearing two types of eye protectors simultaneously $(3 \mathrm{M}$ mono safety glasses and protective screen) decreased visual acuity up to $37 \%$, color visualization up to $25 \%$, and contrast sensitivity up to $75 \%$ within minutes of placement. Nevertheless, the lower quality of vision assessed by an ophthalmological examination cannot be directly translated into worse colonoscopy quality in real endoscopy practices, such as a lower ADR. Taking the findings of previous studies together with the findings of our present study, we suggest that a simple face shield may not interfere with qualified colonoscopy performance, although the effect of wearing complex eye-protecting PPE, such as simultaneously wearing two different types of glasses, a shield, and/ or a screen, may need further research to clarify its potential for unfavorable effects on colonoscopy quality.

Our study had several limitations. First, there could be selection bias of patients because of the COVID-19 pandemic. Healthcare service-seeking behavior could be influenced by the COVID-19 pandemic and the characteristics of persons who visited our center during this pandemic may not represent those of the general population, which limits the generalizability of our study. Second, this was a retrospective study. Colonoscopy insertion time, withdrawal time, and polypectomy time were calculated based on the time recorded on the endoscopy pictures, which may not always be completely correct. Third, we investigated the polypectomy time and adverse events to assess the effect of face shields on therapeutic colonoscopy. However, the primary goal of polypectomy is complete resection of colorectal neoplasm. Therefore, the evaluation of histological complete resection that was not performed in our study may be the most relevant method for assessment of quality of polypectomy, although we confirmed endoscopically complete resection in all cases. Despite these limitations, we believe that our study is meaningful in terms that we confidently showed the absence of unfavorable effect by the face shield on colonoscopy quality indicators, thereby providing a rationale for PPE use against a pandemic caused by aerosol transmission, to improve the safety of endoscopists without loss of colonoscopy quality.

In conclusion, in our experience, colonoscopy performance was not affected by the face shield. Colonoscopy quality indicators, such as ADR, AADR, APC, and withdrawal time, did not worsen when a face shield was worn. In addition, polypectomy-associated indicators, such as polypectomy time and adverse events, were not worse. Therefore, use of the face shield as PPE can be recommended without any concern about colonoscopy performance reduction during this COVID-19 pandemic. 


\section{CONFLICTS OF INTEREST}

No potential conflict of interest relevant to this article was reported.

\section{AUTHOR CONTRIBUTIONS}

Conceptualization, methodology, and data curation: J.W.L., H.J.L., J.S.B. Resources: J.W.L., H.J.L, D.S.K., J.Y., S.W.H., H.W.H., J.S.L., G.U.K., S.L. Formal analysis and visualization: J.W.L., J.S.B. Critical revision: J.C., J.H.P., D.H.Y. Writing - original draft: J.W.L. Overall project administration, and supervision: J.S.B.

\section{ORCID}

Jin Wook Lee https://orcid.org/0000-0002-5312-4053

Hyo Jeong Lee https://orcid.org/0000-0002-5576-4142 Dae Sung Kim https://orcid.org/0000-0002-4881-7883 Jiyoung Yoon https://orcid.org/0000-0001-7448-4296 Seung Wook Hong https://orcid.org/0000-0003-1440-9950 Ha Won Hwang https://orcid.org/0000-0002-4065-5058 Jong-Soo Lee https://orcid.org/0000-0002-8002-2693 Gwang-Un Kim https://orcid.org/0000-0002-4285-5969 Sinwon Lee https://orcid.org/0000-0001-6474-0604 Jaewon Choe https://orcid.org/0000-0002-0393-6803 Jin Hwa Park https://orcid.org/0000-0002-9402-5780 Dong-Hoon Yang https://orcid.org/0000-0001-7756-2704 Jeong-Sik Byeon https://orcid.org/0000-0002-9793-6379

\section{REFERENCES}

1. Wiersinga WJ, Rhodes A, Cheng AC, Peacock SJ, Prescott HC. Pathophysiology, transmission, diagnosis, and treatment of coronavirus disease 2019 (COVID-19): a review. JAMA 2020;324:782-793.

2. Li Q, Guan X, Wu P, et al. Early transmission dynamics in Wuhan, China, of novel coronavirus-infected pneumonia. N Engl J Med 2020;382:1199-1207.

3. Nguyen LH, Drew DA, Graham MS, et al. Risk of COVID-19 among front-line health-care workers and the general community: a prospective cohort study. Lancet Public Health 2020;5:e475-e483.

4. Chu DK, Akl EA, Duda S, et al. Physical distancing, face masks, and eye protection to prevent person-to-person transmission of SARS-CoV-2 and COVID-19: a systematic review and meta-analysis. Lancet 2020;395:1973-1987.

5. Centers for Disease Control and Prevention (CDC). Interim infection prevention and control recommendations for healthcare personnel during the coronavirus disease 2019 (COVID-19) pandemic [Internet]. Atlanta: CDC; c2020 [cited 2020 Jul 22]. Available from: https://www.cdc.gov/ coronavirus/2019-ncov/hcp/infection-control-recommendations.html.

6. Jackson T, Deibert D, Wyatt G, et al. Classification of aerosol-generating procedures: a rapid systematic review. BMJ Open Respir Res 2020;7:e000730.

7. Sultan S, Lim JK, Altayar O, et al. AGA rapid recommendations for gastrointestinal procedures during the COVID-19 pandemic. Gastroenterology 2020;159:739-758.

8. Chiu PWY, Ng SC, Inoue H, et al. Practice of endoscopy during COVID-19 pandemic: position statements of the Asian Pacific Society for Digestive Endoscopy (APSDECOVID statements). Gut 2020;69:991-996.

9. Gralnek IM, Hassan C, Beilenhoff U, et al. ESGE and ESGENA Position Statement on gastrointestinal endoscopy and the COVID-19 pandemic. Endoscopy 2020;52:483-490.

10. Repici A, Maselli R, Colombo M, et al. Coronavirus (COVID-19) outbreak: what the department of endoscopy should know. Gastrointest Endosc 2020;92:192-197.

11. Choi JH, Cha JM, Yoon JY, Kwak MS, Jeon JW, Shin HP. The current capacity and quality of colonoscopy in Korea. Intest Res 2019;17:119-126.

12. Rex DK, Schoenfeld PS, Cohen J, et al. Quality indicators for colonoscopy. Gastrointest Endosc 2015;81:31-53.

13. Min JK, Cha JM, Cho YK, et al. Revision of quality indicators for the endoscopy quality improvement program of the National Cancer Screening Program in Korea. Clin Endosc 2018;51:239-252.

14. Kim MC, Bae S, Kim JY, et al. Effectiveness of surgical, KF94, and N95 respirator masks in blocking SARS-CoV-2: a controlled comparison in 7 patients. Infect Dis (Lond) 2020;52:908-912.

15. Lai EJ, Calderwood AH, Doros G, Fix OK, Jacobson BC. The Boston Bowel Preparation Scale: a valid and reliable instrument for colonoscopy-oriented research. Gastrointest Endosc 2009;69(3 Pt 2):620-625.

16. Park SK, Kim HY, Lee CK, et al. Comparison of adenoma detection rate and adenoma per colonoscopy as a quality indicator of colonoscopy. Scand J Gastroenterol 2016;51:886890.

17. Jung Y, Cha JM, Lee NH, et al. Impact of endoscopists' personality traits on adenoma and polyp detection rates in colonoscopy: a KASID multicenter study. Dig Dis Sci 2020;65:2302-2310.

18. Yoon JY, Cha JM, Jeen YT; Medical Policy Committee of Korean Association for the Study of Intestinal Diseases (KASID); Quality Improvement Committee of Korean Society of Gastrointestinal Endoscopy (KSGE). Quality is the key for 
emerging issues of population-based colonoscopy screening. Clin Endosc 2018;51:50-55.

19. Kaminski MF, Wieszczy P, Rupinski M, et al. Increased rate of adenoma detection associates with reduced risk of colorectal cancer and death. Gastroenterology 2017;153:98105.

20. Kaminski MF, Regula J, Kraszewska E, et al. Quality indicators for colonoscopy and the risk of interval cancer. N Engl J Med 2010;362:1795-1803.

21. Adler A, Wegscheider K, Lieberman D, et al. Factors determining the quality of screening colonoscopy: a prospective study on adenoma detection rates, from 12,134 examinations (Berlin colonoscopy project 3, BECOP-3). Gut 2013;62:236241.

22. Gurudu SR, Ramirez FC, Harrison ME, Leighton JA, Crowell MD. Increased adenoma detection rate with system-wide implementation of a split-dose preparation for colonoscopy. Gastrointest Endosc 2012;76:603-608.

23. Barclay RL, Vicari JJ, Greenlaw RL. Effect of a timedependent colonoscopic withdrawal protocol on adenoma detection during screening colonoscopy. Clin Gastroenterol Hepatol 2008;6:1091-1098.

24. Baxter NN, Sutradhar R, Forbes SS, Paszat LF, Saskin R, Ra- beneck L. Analysis of administrative data finds endoscopist quality measures associated with postcolonoscopy colorectal cancer. Gastroenterology 2011;140:65-72.

25. Wong MC, Ding H, Wang J, Chan PS, Huang J. Prevalence and risk factors of colorectal cancer in Asia. Intest Res 2019;17:317-329.

26. Brenner H, Hoffmeister M, Stegmaier C, Brenner G, Altenhofen L, Haug U. Risk of progression of advanced adenomas to colorectal cancer by age and sex: estimates based on 840,149 screening colonoscopies. Gut 2007;56:1585-1589.

27. Celtikci E, Karaaslan B, Börcek AÖ, Emmez OH. Reduced field of view under the surgical microscope due to personal protective equipment: lessons learned during the COVID-19 pandemic. Neurosurg Focus 2020;49:E15.

28. Iyer A, Tikka T, Calder N, Qamar SN, Chin A. Effect of personal protection equipment (PPE) and the distance from the eye piece of surgical microscope on the field of vision: an experimental study. Otol Neurotol 2021;42:606-613.

29. Rincón Sánchez RA, Concha Mejía A, Viaña Ríos LM. Quality of vision in endoscopy in the midst of a pandemic: does PPE influence quality of vision during gastrointestinal endoscopy? Gastroenterol Hepatol 2021;44:637-643. 